\title{
Serum Water Analysis in Normal Pregnancy and Preeclampsia
}

\section{SHARON STOSUR, NING LIU, STEPHANIE RODRIGUES, CARLOS SANDOVAL-HERRERA, LILLIAN MUNDT, JACK GARON}

\begin{abstract}
Hemodilution and hemoconcentration affect hematology measurements and serum analyte concentrations but whether a given blood sample is hemodiluted or hemoconcentrated is frequently not known. Preeclampsia (PE) is a serious pregnancy complication and samples obtained from PE patients may be relatively hemoconcentrated when compared to those of normal pregnancy, where hemodilution is the norm. Laboratory test results may appear similar when values would differ if adjusted for hemodilution and hemoconcentration. We sought to determine if serum water (SW) content analysis can facilitate differentiation of the hemodilution of normal pregnancy from the hemoconcentration of PE, within the broader search of a clinical laboratory method to potentially correct for pregnancy-related, sample concentration variations.
\end{abstract}

Serum samples from 59 non-pregnant, 64 normal pregnant, 23 mild PE, and 8 severe PE patients were tested for SW content. The mean results in $\mathrm{g} / 100 \mathrm{~g}$ were as follows: $91.15,91.86,92.00$, and 92.46 respectively. SW data were also compared with corresponding total protein (TP), serum albumin (SA), and hematocrit (HCT) results. The $t$-test was significant $(p=<0.001)$ for TP, SA, HCT, and SW in group-by-group comparisons. SA and SW were significantly, inversely correlated in the normal pregnant and severe PE groups, while TP and SW were significantly, inversely correlated in all groups. Correlation coefficients were stronger in the pregnancy groups than the non-pregnant group. This study demonstrates differences in the SW content between: non-pregnant, normal pregnant, mild $\mathrm{PE}$, and severe PE patient sera.
ABBREVIATIONS: $\mathrm{PE}=$ Preeclampsia, $\mathrm{SW}=$ Serum water, $\mathrm{TP}=$ Total protein, $\mathrm{SA}=$ Serum albumin, HCT $=$ Hematocrit, $\mathrm{CH}=$ Chronic Hypertension.

INDEX TERMS: hemoconcentration, hemodilution, plasma volume, preanalytical, pregnancy, preeclampsia, serum water.

Clin Lab Sci 2011;24(2):99

Sharon Stosur, MS, MLS(ASCP) $)^{C M}$, Arlington Heights, IL

Ning Liu, PhD, Mount Sinai Hospital, Chicago, IL

Stephanie Rodrigues, SC, Mount Sinai Hospital, Chicago, IL

Carlos Sandoval-Herrera, MD, Mount Sinai Hospital, Chicago, IL

Lillian Mundt EdD, MLS(ASCP) SH, Lombard, IL

Jack Garon, MD, Mount Sinai Hospital, Chicago, IL

Address for Correspondence: Sharon Stosur, MS, MLS $(A S C P)^{C M}$, PO Box 534 Arlington Heights, IL 60006, 847.870.7278, stosursharon@live.com

\section{INTRODUCTION}

Increased plasma volume results in generalized hemodilution which is a patient-related variable. ${ }^{1}$ Normal pregnancy is characterized by hemodilution as plasma volume increases markedly, while $\mathrm{PE}$ is characterized by relative hemoconcentration. Hemoconcentration causes solutes that are unchanged 


\section{RESEARCH AND REPORTS}

to appear elevated and those that have decreased may go unnoticed. ${ }^{2}$

\section{Hemodilution in normal pregnancy}

Total plasma volume increases about 45\% during normal pregnancy, while the blood volume increases about $33 \%$, in essence the increment in plasma exceeding that of the red cell volume, resulting thus in a decrease in the HCT. ${ }^{3-5}$ SA concentrations are also decreased in normal pregnancy, the normal increase in maternal plasma volume accounting for reduced SA concentrations. ${ }^{6,7}$ The total intravascular mass of albumin is comparable to that of non-pregnant women, thus hemodilution accounts for the $-1 \mathrm{gm} / \mathrm{dL}$ in SA decrement in normal gestation. ${ }^{3}$

\section{Hemoconcentration in preeclampsia}

$\mathrm{PE}$ is associated with hypovolemia and hemoconcentration, and severity is evidenced clinically by a rising HCT. ${ }^{8}$ Also, blood volume may be reduced as much as 35 to 50 percent. $^{8}$ Friedman and Young's Effects of Disease on Clinical Laboratory Tests provides data on analytes that are increased, decreased, or unchanged in various disease states. More than 50 analytes are increased in PE compared to normal pregnancy, serum viscosity is increased, and a number of analytes are decreased. ${ }^{7}$ Consistent trends demonstrate a patient-related, preanalytical variable in PE. In general, the analytes that are elevated in PE compared to normal pregnancy are more elevated in severe PE than in mild PE; and when analytes are decreased in PE compared to normal pregnancy, the decrement is greater in severe PE than in mild PE.

\section{Serum albumin and hypovolemia in PE}

SA is consistently decreased in PE, the patients thus manifesting decreased oncotic pressure resulting in more intravascular fluid entering or remaining in the extravascular space. ' Lower albumin levels and the degree of hypovolemia correlate with disease severity. ${ }^{6,9}$ Hypovolemia and hypoalbuminemia precede the onset of $\mathrm{PE}$, and in the absence of other disease processes, hypovolemia precedes the disorder unequivocally. ${ }^{6}$ Colloid osmotic pressure decreases result in relative hemoconcentration, and simultaneous marked generalized edema and contracted plasma volume suggest that PE patients are "dehydrated" into their interstitial spaces. ${ }^{8}$

\section{Normal pregnancy reference ranges}

Reference ranges are traditionally derived from blood samples obtained from healthy males and healthy, nonpregnant females. Laboratory test results within range for a non-pregnant adult may be abnormal during gestation, thus, normal pregnancy reference tables have been developed for clinicians. ${ }^{10,11}$ Notwithstanding, hemodilution characteristic of normal pregnancy reduces analyte concentrations non-specifically, unless an absolute increase accompanies hemodilution. Normal pregnancy reference ranges will reflect hemodiluted analyte concentrations. The opposite effect, hemoconcentration, may cause PE patient test results to fall within normal ranges, when absolute values of analytes have decreased, creating false-normal results.

\section{Serum water determination}

Gravimetric analysis is a method that utilizes weight loss for quantitative determination of an analyte. Weight is a property that can be measured with great accuracy, and water is the chief component of serum. SW content analysis by this method involves subjecting a serum sample to a process of an initial weight determination, oven drying to a constant weight by two consecutive readings, followed by performing a calculation for the SW content in $\mathrm{g} / 100 \mathrm{~g}{ }^{2}$

\section{MATERIALS AND METHODS}

SW content analysis was performed on randomly selected samples obtained from non-pregnant and pregnant patients, on which comprehensive metabolic panel analyses had previously been performed. SW $(\mathrm{g} / 100 \mathrm{~g})$ was determined using samples from 59 male and non-pregnant female adults, 64 normal pregnant third trimester patients, 23 mild PE patients, and 8 severe PE patients. Excluded from the study were samples from patients with laboratory evidence of diabetes, hepatic, or renal disease, and post-partum samples. An initial review of the data revealed that all $31 \mathrm{PE}$ cases were in the third trimester, thus, in order to maintain a control group equal by gestational time, only third trimester normal pregnant patient results were included in the data analysis. Samples from pregnant 


\section{RESEARCH AND REPORTS}

patients with diabetes, and first and second trimester normal pregnant patient samples were analyzed for SW, were not included in the data analysis, and are discussed separately.

Serum samples were previously analyzed on the Beckman Coulter DxC 800 Chemistry analyzer, and phlebotomy time-matched blood samples were analyzed on the Beckman Coulter LH 750 Hematology Analyzer, in the laboratories of Mount Sinai Hospital.

Serum samples were stored at $5^{\circ} \mathrm{C}$ in the Lab-Line Ambi Hi-Lo Chamber. Aluminum weigh boats $(43 \mathrm{~mm}$ diameter by $12 \mathrm{~mm}$ high) were pre-dried 4 hours at $120^{\circ} \mathrm{C}$ and stored in a dessicator jar until used. Weights were taken on the Mettler AJ100 balance scale, which is readable to $0.0001 \mathrm{~g}$. Samples were added to pre-dried pans on the balance scale, weighed, and placed in the Baxter DX31 drying oven, preheated to $75-85^{\circ} \mathrm{C}$. Weights were obtained after one hour, and every 10-15 minutes thereafter, until two readings were constant within $0.0002 \mathrm{~g}$. The formula used to determine SW was previously described by Ohira and associates, where: Serum water $(\mathrm{g} / 100 \mathrm{~g})=$ total serum weight dried solid weight $\} \times 100 /$ total serum weight. ${ }^{2}$ Data analysis was performed using Excel 2003 and SPSS ${ }^{\oplus}$ 18.0 statistical software.

Pregnancy cases were categorized according to criterion established by the American College of Obstetricians and Gynecologists (ACOG) including their criteria for mild and severe PE. ${ }^{12} \mathrm{PE}$ diagnosis requires a blood pressure reading of $\geq 140 \mathrm{mmHg}$ systolic or $\geq 90 \mathrm{mmHg}$ diastolic occuring in a woman more than 20 weeks gestation, whose blood pressure was previously normal, and proteinuria defined as $\geq 0.3 \mathrm{~g}$ in a 24 -hour urine sample. ${ }^{12}$ Diagnostic criteria for severe PE includes: blood pressure of $\geq 160 \mathrm{mmHg}$ systolic or $\geq 110 \mathrm{mmHg}$ diastolic in two readings 6 or more hours apart; protein of $\geq 5 \mathrm{~g}$ in a 24 -hour urine sample, or $\geq 3+$ protein on two random urine samples collected at 4 or more hours apart; oliguria $<500 \mathrm{ml}$ in 24 hours; cerebral or visual disturbances; pulmonary edema or cyanosis; epigastric or upper-quadrant pain; impaired liver function; thrombocytopenia; fetal growth restriction. ${ }^{12}$ This study took place in 2009-2010. The Institutional Review Boards of Mount Sinai Hospital and Rosalind Franklin
University of Medicine and Science approved the protocol.

\section{RESULTS - Serum Water}

SW (g/100g) means for the non-pregnant, normal pregnant, mild $\mathrm{PE}$, and severe $\mathrm{PE}$ groups were as follows: 91.15, 91.86, 92.00, and 92.46, respectively. $\mathrm{TP}(\mathrm{g} / \mathrm{dL})$ means for the respective groups were as follows: $6.96,5.80,5.62$, and 5.31.

Figures 1. and 2. are boxplots created using SPSS ${ }^{\circledR} 18.0$ statistical software showing the data distribution including median, interquartile range, and smallest and largest values for each group. Each box extends from the 25 th to 75 th percentiles, the horizontal line inside the box is the median, and the vertical lines represent smallest to largest values within 1.5 box lengths. The circles represent individual, extreme values.

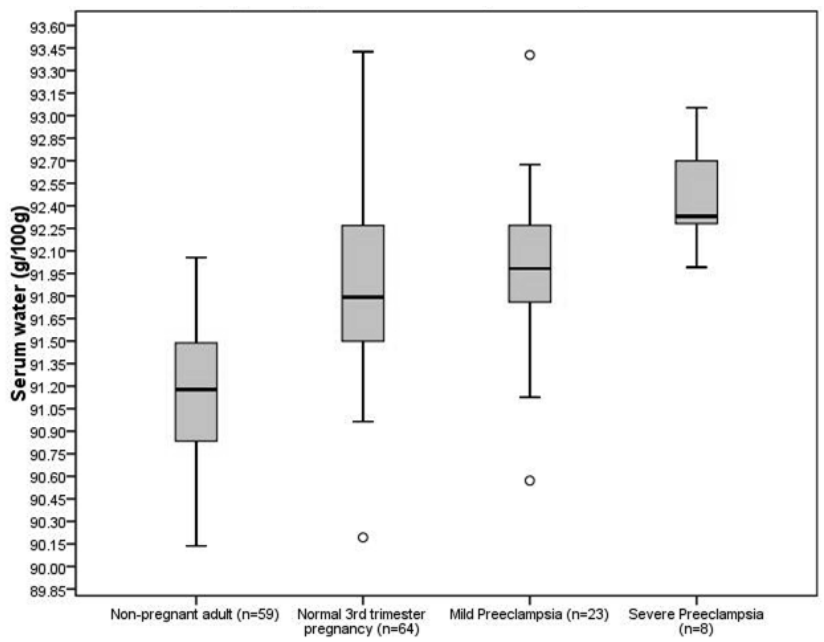

Figure 1. Serum Water $(\mathrm{g} / 100 \mathrm{~g})$ in Non-pregnant Adults, 3rd Trimester Normal Pregnancy, Mild PE, and Severe PE

\section{T-test data analysis}

The $t$-test, 95\% confidence interval, was significant $(p=$ $<0.001)$ for each: TP, SA, SW content and HCT in the following group comparisons:

a.) Non-pregnant adult and third trimester normal pregnant

b.) Third trimester normal pregnant and mild PE

c.) Mild preeclampsia and severe PE

d.) Normal third trimester and severe PE 


\section{RESEARCH AND REPORTS}

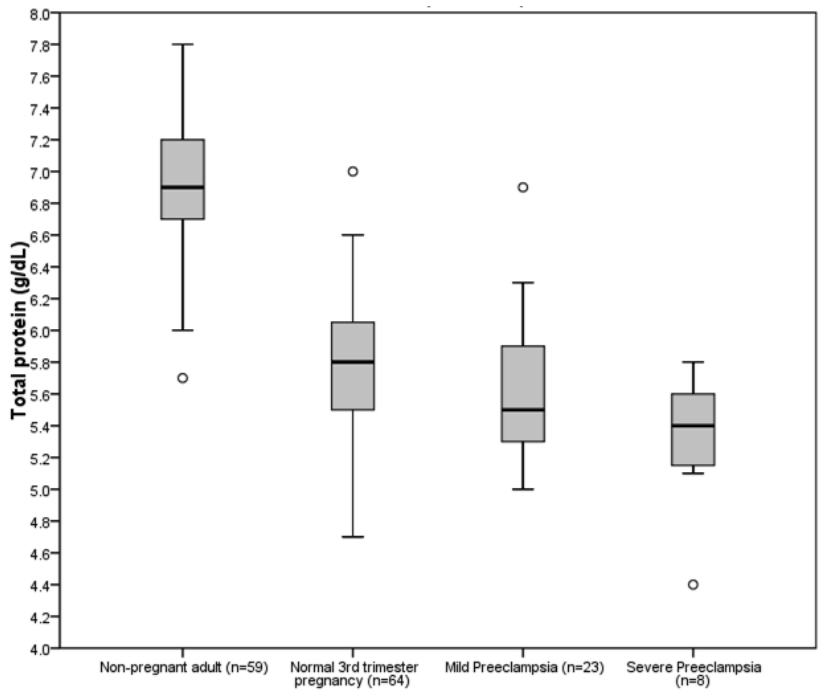

Figure 2. Total Protein $(\mathrm{g} / \mathrm{dL})$ in Non-pregnant Adults, 3rd Trimester Normal Pregnancy, Mild PE, and Severe PE

The means, standard deviations, and spread determined for TP, SA, SW content, and HCT for each group are shown in Table 1.

\section{Data analysis results - Pearson's correlation}

Pearson's correlation analysis yielded statistically significant results when TP was correlated with SW in all groups. The relationship was inverse, so as TP decreases, SW content increases. SA was correlated with SW in all groups; the normal pregnancy and severe PE groups yielded statistically significant results while the mild PE group and the non-pregnant group lacked statistical significance. HCT results were analyzed for correlation with SW, and lacked statistical significance in all groups. The inverse correlations were greater for TP and SW than SA and SW, and all inverse correlations were greater in the pregnancy groups than the non-pregnant group. The results are shown in Table 2.

\section{Serum water analysis as a potential marker for $P E$}

SW was increased above the normal third trimester mean in 24/31 PE cases, and the remainder were from the mild PE group. In contrast, HCT was decreased be-

Table 1. Total Protein, Serum Albumin, Serum Water, and Hematocrit in non-pregnant adults, 3rd trimester normal pregnancy, mild and severe preeclampsia

\begin{tabular}{|c|c|c|c|c|c|}
\hline $\begin{array}{l}\text { Analyte / } \\
\text { Ref range }\end{array}$ & & $\begin{array}{l}\text { Non-preg } \\
n=59\end{array}$ & $\begin{array}{l}\text { Third Tri N } \\
n=64\end{array}$ & $\begin{array}{l}\text { Mild PE } \\
n=23\end{array}$ & $\begin{array}{l}\text { Severe PE } \\
n=8\end{array}$ \\
\hline Total protein $\mathrm{g} / \mathrm{dL}$ & mean & 6.96 & 5.80 & 5.62 & 5.31 \\
\hline Ref range $6.4-8.3 \mathrm{~g} / \mathrm{dL}$ & $\begin{array}{l}\text { S.D. } \\
\text { spread }\end{array}$ & $\begin{array}{l}0.44 \\
(5.7-8.2)\end{array}$ & $\begin{array}{l}0.49 \\
(4.7-7.0)\end{array}$ & $\begin{array}{l}0.46 \\
(5.0-6.9)\end{array}$ & $\begin{array}{l}0.44 \\
(4.4-5.8)\end{array}$ \\
\hline Serum albumin $\mathrm{g} / \mathrm{dL}$ & mean & 4.03 & 2.73 & 2.68 & 2.46 \\
\hline Ref range $3.5-5.0 \mathrm{~g} / \mathrm{dL}$ & $\begin{array}{l}\text { S.D. } \\
\text { spread }\end{array}$ & $\begin{array}{l}0.27 \\
(3.4-4.5)\end{array}$ & $\begin{array}{l}0.29 \\
(2.1-3.4)\end{array}$ & $\begin{array}{l}0.28 \\
(2.2-3.3)\end{array}$ & $\begin{array}{l}0.44 \\
(1.5-2.9)\end{array}$ \\
\hline Serum water $\mathrm{g} / 100 \mathrm{~g}$ & mean & 91.15 & 91.86 & 92.00 & 92.46 \\
\hline Ref range (none) & $\begin{array}{l}\text { S.D. } \\
\text { spread }\end{array}$ & $\begin{array}{l}0.46 \\
(90.14-92.06)\end{array}$ & $\begin{array}{l}0.54 \\
(90.19-93.42)\end{array}$ & $\begin{array}{l}0.57 \\
(90.57-93.4)\end{array}$ & $\begin{array}{l}0.33 \\
(91.99-93.05)\end{array}$ \\
\hline $\begin{array}{l}\text { Hematocrit } \% \\
\text { Ref range } 36-46 \%\end{array}$ & $\begin{array}{l}\text { mean } \\
\text { S.D. } \\
\text { spread }\end{array}$ & $\begin{array}{l}39.27 \\
2.74 \\
(33.1-45.7)\end{array}$ & $\begin{array}{l}34.14 \\
3.12 \\
(25.0-40.4)\end{array}$ & $\begin{array}{l}33.08 \\
2.56 \\
(29.6-39.5)\end{array}$ & $\begin{array}{l}31.70 \\
3.49 \\
(28.7-38.4)\end{array}$ \\
\hline
\end{tabular}

Abbreviations: Non-preg = non-pregnant adults; Third Tri $\mathrm{N}=$ third trimester normal pregnancy; Mild PE $=$ mild preeclampsia; Severe PE $=$ Severe Preeclampsia; S.D. = standard deviation; Spread = range of observed values; ref range = reference ranges used at Mt. Sinai Hospital in Chicago, Illinois.

low the normal third trimester mean in 21/31 PE cases; TP was decreased below the normal third trimester mean in 23/31 PE cases; and SA was decreased below the normal third trimester mean in 16/31 PE cases. 


\section{RESEARCH AND REPORTS}

Data analysis exclusions - first and second trimester, and diabetes

Eight samples were analyzed for SW from patients in the first trimester. Of the eight, one was diabetic. Excluding the diabetic case, the mean SW for the first trimester was $91.30 \mathrm{~g} / 100 \mathrm{~g}$. An additional eight samples were obtained from second trimester patients. The mean SW for the second trimester was $91.93 \mathrm{~g} / 100 \mathrm{~g}$. SW for the first trimester diabetic case was $92.04 \mathrm{~g} / 100 \mathrm{~g}$. which is comparable to the mild PE mean $92.00 \mathrm{~g} / 100 \mathrm{~g}$. A normal third trimester diabetic case re-

Table 2. Pearson's correlation results between serum proteins and serum water.

\begin{tabular}{llcccccc}
\hline & & \multicolumn{3}{c}{ Total protein : serum water } & \multicolumn{3}{c}{ Serum albumin : serum water } \\
& $\mathbf{n}$ & $\mathbf{r}$ & sig 2-tailed & sig level & $\mathbf{r}$ & sig 2-tailed & sig level \\
Non-pregnant group & 59 & -.697 & 0.000 & $(0.01)$ & -.200 & 0.129 & neg \\
Normal 3rd trimester & 64 & -.817 & 0.000 & $(0.01)$ & -.548 & 0.000 & $(0.01)$ \\
Mild PE & 23 & -.756 & 0.000 & $(0.01)$ & -.404 & 0.056 & neg \\
Severe PE & 8 & -.884 & 0.004 & $(0.01)$ & -.806 & 0.016 & $(0.05)$ \\
\hline
\end{tabular}

Abbreviations: $n=$ number of cases; $r=$ correlation coefficient; sig = significance; neg = negligible significance (greater than 0.05 ).

sulted a SW of $91.99 \mathrm{~g} / 100 \mathrm{~g}$ while yet another diabetic patient was mildly preeclamptic at 35 weeks gestation, and yielded a SW result of $93.48 \mathrm{~g} / 100 \mathrm{~g}$. Diabetes is a known risk factor for PE.

\section{Chronic hypertension}

A total of 7 chronic hypertensive $(\mathrm{CH})$ patient samples were included in their respective groups because the data revealed no appreciable difference in laboratory test results compared to non- $\mathrm{CH}$ test results. Of the $\mathrm{CH}$ cases, 3 were normal pregnant; 3 had mild PE; and 1 had severe PE.

\section{CONCLUSION / DISCUSSION}

As establishment of normal pregnancy reference ranges appears imminent, clinical laboratory scientists may do well to consider the total plasma volume (differences) between normal pregnant and PE patients that result in hemodilution and relative hemoconcentration. These conditions create opposing, preanalytical variables both of which occur in the pregnant patient population. The premise that SW content analysis might help differentiate the two, alone or in combination with select analytes, required first that we determine whether differences in SW content occur between the patient populations of interest.

The mean SW content in mild PE was higher than in normal pregnancy and higher still in severe PE, a conspicuous gradient well shown by our database. Thus, in addition to the generally recognized reduction of total plasma volume in $\mathrm{PE}$ compared to normal pregnancy, we have demonstrated that there is also more water per unit volume. This result seems counterintuitive in one aspect because of the equally well known reduced SA in PE with increased viscosity of serum. One possible explanation for this, not specifically addressed by this study, is the concurrent relative increase in serum globulins. Decreased total intravascular plasma protein may explain increased mean SW content in PE samples compared to those of normal pregnancy, and may provide a premise for future studies.

Our work agrees with the work of Ohira and associates, and adds new data that inverse correlations between serum proteins and SW content are stronger during pregnancy than in non-pregnant adults. Our study also agrees with the observation made by Gojnic and associates, who reported that $100 \%$ of SA values were lower than $3.0 \mathrm{~g} / \mathrm{dL}$ in the severe PE cases.

Whether SW content analysis can provide differentiation of the hemodilution of normal pregnancy from the relative hemoconcentration of $\mathrm{PE}$ is inconclusive, since overlapping values were observed. However, the direction of change in SW content between the patient groups is hereby demonstrated. Prior research has shown the changes that occur in total plasma volume during normal pregnancy and PE; our study focused on SW content analysis without performing individual, total plasma volumes. 


\section{RESEARCH AND REPORTS}

Simultaneous assessment of total plasma volumes and SW analysis may therefore prove useful in future studies.

\section{Limitations of the study}

Salvaged samples were used, and while automated testing methods limit exposure to air, some variability in the handling of samples may have occurred prior to samples being obtained for SW analysis. Total plasma volumes were unknown, and patients' liquid intakes prior to phlebotomy procedures were not known; if available, this information may have improved our results.

\section{Acknowledgements:}

We would like to thank Mary Maynerich, Manager of the Hematology department of Mount Sinai Hospital; professors Rudolph L. Engman and Daniel J. Stanford, PhD., of Harper College for early insights on the project idea; Brandon J. Knecht and Russell Puetz for statistical advice; and Professors Emeritus: Douglas R. Shanklin, M.D., FRSM, and Marshall D. Lindheimer, M.D., FACP, FRCOG (London, ad eundum), who, without their many consultations, practical guidance, and mentorship, this study would never have begun, nor made it to completion.

\section{REFERENCES}

1. Allen M. The Preanalytical Phase: An Important Component of Laboratory Medicine. Pathology Update The Dept. of Pathology, Texas Tech University Health Sciences Center at El Paso, No. 3 Mar. 7, 2002.

2. OhiraY, Ito A, Ikawa S. Correction of water content and solute concentration in blood during hemoconcentration J. Appl.
Physiol: Respirat. Environ. Exercise Physio. 1977;42(5):73943.

3. Conrad KP, Gaber LW, Lindheimer MD. The kidney in normal pregnancy and preeclampsia, Chap. 17. In Chesley's Hypertensive disorders in pregnancy, 3rd edition, Lindheimer MD, Roberts JM, Cunningham, FG. eds, San Diego, Academic Press, Elsevier, 2009;297-334.

4. Goodlin RC, Dobry CA, Anderson JC, et al. Clinical signs of normal plasma volume expansion during pregnancy. Am. J. Obstet. Gynecol. 1983;145:1001.

5. Blekta M, Hlavaty V, Trnkova M, et al. Volume of whole blood and absolute amount of serum proteins in the early stage of late toxemia of pregnancy. Amer. J. Obstet. Gynec. 1970; 106;1:10-3.

6. Shanklin DR. Physiological and pathophysiological effects of malnutrition, Chap. 5. In Maternal Nutrition and Child Health, 2nd edition, Charles C Thomas Publisher LTD 2000; 71-123.

7. Friedman RB, Young DS. Pregnancy, complications of pregnancy and the puerperium. In Effects of Disease on Clinical Laboratory Tests, 3rd edition, AACC Press. 1997; 4386-4-394.

8. Brewer TH, Abnormal physiology and biochemistry: hypovolemia, hemoconcentration, hypoalbuminemia. Chap. 4. In Metabolic toxemia of late pregnancy: a disease of malnutrition. Keats Publishing, 1982;14-66.

9. Gojnic M, Petkovic S, Papic M, et al. Plasma albumin level as an indicator of severity of preeclampsia. Clin. Exp. Obst. \& Gyn. 2004;209-10.

10. Larsson A, Palm M, Hansson L, Axelsson O. Reference values for clinical chemistry tests during normal pregnancy. BJOG 2008;115:874-881.

11. Abbassi-Ghanavati M, Greer LG, Cunningham FG. Pregnancy and Laboratory Studies: A Reference Table for Clinicians. Obstet. Gynecol. 2009;114:1326-31.

12. ACOG Practice Bulletin Clinical Management Guidelines for Obstetrician-Gynecologists Diagnosis and Management of Preeclampsia and Eclampsia. American College of Obstetricians and Gynecologists. Obstet. Gynecol. 2002; 99: 159-67.

The peer-reviewed Research and Reports Section seeks to publish reports of original research related to the clinical laboratory or one or more subspecialties, as well as information on important clinical laboratory-related topics such as technological, clinical, and experimental advances and innovations. Literature reviews are also included. Direct all inquiries to David $L$ McGlasson MS, MLS, 59th Clinical Research Division/SGRL, 2200Berquist Dr., Bldg. 4430, Lackland AFB TX 782369908,david.mcglasson@lackland.af.mil

Clinical Laboratory Science encourages readers to respond with thoughts, questions, or comments regarding these articles. Email responses towestminsterpublishers@comcast.net.In the subject line, please type the journal issue and lead author such as "CLIN LAB SCI 24(2) RE STOSUR". Selected responses may appear in the Dialogue and Discussion section in a future issue. Responses may be edited for length and clarity. We look forward to hearing from you. 